\title{
Avaliação da eficácia da tintura etanólica de guaco (Mikania glomerata) no controle da podridão negra (Xanthomonas campestris pv. campestris) em couve-flor ${ }^{1}$
}

\section{Effect of alcoholic extract of guaco (Mikania glomerata) on the control of dark rot (Xanthomonas campestris pv. campestris) in cauliflower}

\author{
Sandra Cristina Vigo-Schultz² ; José Renato Stangarlin ${ }^{3 *}$; Gilmar Franzener ${ }^{4}$; \\ Roberto Luiz Portz ${ }^{5}$; Odair José Kuhn ${ }^{6}$; Kátia Regina Freitas Schwan-Estrada ${ }^{7}$
}

Resumo

Com a prática da irrigação e novos híbridos de couve-flor, é possível produzir durante todo o ano e com alta produtividade. Mas, a cultura tem sido afetada por doenças a exemplo da podridão negra causada por Xanthomonas campestris pv. campestris, fomentando novas pesquisas para seu controle. Com o objetivo de verificar o potencial de Mikania glomerata no controle dessa doença, a tintura etanólica 50 ${ }^{\circ} \mathrm{GL}$ dessa planta medicinal foi avaliada quanto: atividade antimicrobiana in vitro através do crescimento bacteriano em tubos de ensaio contendo $100,250,500$ e $1000 \mathrm{mg} \mathrm{L}^{-1}$ da tintura; indução de resistência local ou sistêmica em plantas de couve-flor aos 25 dias de idade, em casa de vegetação, através da pulverização de tintura concomitantemente e três dias antes da inoculação com o patógeno, sendo água e calda bordaleza tratamentos controle; atividade de peroxidases em folhas tratadas e não tratadas de couve-flor, colhidas concomitantemente e as 24,48 e $72 \mathrm{~h}$ da pulverização da tintura e, após pulverizaçãoinoculação. A tintura etanólica, in vitro, promoveu inibição no crescimento bacteriano, a partir da concentração de $250 \mathrm{mg} \mathrm{L}^{-1}$. Nas concentrações de $500 \mathrm{mg} \mathrm{L}^{-1}$ e $1000 \mathrm{mg} \mathrm{L}^{-1}$ foram observadas, respectivamente, $24 \%$ e $38 \%$ de inibição do crescimento bacteriano. Nas plantas de couve-flor foi observada redução da doença apenas em folhas tratadas com 100 e $500 \mathrm{mg} \mathrm{L}^{-1}$ de tintura, aplicada concomitantemente à inoculação, comportamento este semelhante ao da calda bordaleza, indicando que o controle através da tintura de guaco é através de atividade antimicrobiana direta. Ficou indicado que a indução de peroxidases ocorreu devido ao processo infeccioso e não em função dos tratamentos com tintura etanólica de guaco. Estes resultados indicam o potencial da tintura de guaco para o controle preventivo da podridão negra em couve-flor.

Palavras-chave: Controle alternativo, peroxidase, plantas medicinais, fisiologia do parasitismo.

1 Parte da dissertação de Mestrado do $1^{\circ}$ autor

2 Doutoranda em Agronomia (Proteção de Plantas), Departamento de Defesa Fitossanitária, Faculdade de Ciências Agronômicas, UNESP, Botucatu, SP. Bolsista da Capes

3 Professor Adjunto da Universidade Estadual do Oeste do Paraná (UNIOESTE), Centro de Ciências Agrárias, Rua Pernambuco 1777, Caixa Postal 1008, CEP 85960-000, Marechal Cândido Rondon, PR. E-mail: jrstangarlin@unioeste.br. Bolsista de Produtividade em Pesquisa do CNPq.

4 Técnico de Laboratório da Universidade Estadual do Oeste do Paraná (UNIOESTE), Centro de Ciências Agrárias, Mal. Cândido Rondon, PR.

5 Doutorando da Universidade Técnica de Munique, Alemanha.

6 Doutorando do Setor de Fitopatologia da ESALQ/USP, Piracicaba, SP.

7 Professora Adjunta do Departamento de Agronomia, Universidade Estadual de Maringá (UEM), Maringá, PR. Bolsista de Produtividade em Pesquisa do CNPq.

* Autor para correspondência

Recebido para publicação 08/02/06 Aprovado em 04/08/06 


\begin{abstract}
With the use of irrigation and new hybrids of cauliflower, it is possible to get production during all the year with hight yield. However, the crop has been affected by diseases, as the dark rot caused by $X$. campestris pv. campestris. The objective of this research work was to study the potential of Mikania glomerata for the control of this disease. Alcoholic extract $50{ }^{\circ} \mathrm{GL}$ of $M$. glomerata was evaluated regarding to: in vitro antimicrobial activity through bacterial growth in 100, 250, 500 and $1000 \mathrm{mg} \mathrm{L}^{-1}$ of the alcoholic extract; induction of local or systemic resistance in 25 days old cauliflower, with spray of alcoholic extract concomitantly and three days before the inoculation with the pathogen (water and bordeau mixture were used as control); peroxidases activity in leaves of cauliflower treated and not treated, and harvested concomitantly, 24, 48 and 72 hours after spraying the alcoholic extract and also after inoculation. The alcoholic extract of M. glomerata showed inhibition of the bacterial growth in vitro at the concentrations of 250,500 and $1000 \mathrm{mg} \mathrm{L}^{-1}$. The concentrations of $500 \mathrm{mg} \mathrm{L}^{-1}$ and $1000 \mathrm{mg} \mathrm{L}^{-1}$ inhibited $24 \%$ and $38 \%$ of the bacterial growth. This inhibition could be due to antibacterial compounds in the alcoholic extract. An inhibition of the disease in vivo occurred only in the leaves treated with 100 and $500 \mathrm{mg} \mathrm{L}^{-1}$ of alcoholic extract when applied concomitantly with the bacteria. This result was similar to bordeau mixture, indicating a control by direct antimicrobial activity. There was no systemic resistence induction for all treatments. The peroxidases induction was due to infectious pathogen process and not to the treatments with alcoholic extract. The results indicate the potential of M. glomerata alcoholic extract for the preventive control of cauliflower dark rot disease.
\end{abstract}

Key words: Alternative control, peroxidase, medicinal plants, physiology of plant pathology.

\section{Introdução}

O controle de doenças de plantas, tradicionalmente, é realizado com a aplicação de produtos químicos. Esta, por sua vez, pode ser realizada de maneira abusiva e indiscriminada, gerando poluição ambiental e seleção de patógenos resistentes a esses produtos (GHINI; KIMATI, 2000). As plantas medicinais possuem em sua composição substâncias as quais podem exercer funções importantes na interação planta-patógeno, seja ativando os mecanismos de defesa da planta ou atuando como substâncias fungitóxicas à semelhança dos fungicidas sintéticos. Também extratos, tinturas e/ou óleos essenciais destas plantas têm como vantagem o fato de não poluírem o ambiente e serem considerados como alternativa no controle de fitopatógenos (STANGARLIN et al., 1999), seja com ação fungitóxica (BONALDO et al., 2004; FIORI et al., 2000) ou bactericida (BECKER, 2003; KARAMAN et al., 2003; KUHN et al., 2006) ou pela indução de respostas de defesa da planta, através de fitoalexinas, peroxidases e proteínas relacionadas à patogênese (KAGADE et al., 2004; SCHWANESTRADA, 2003), o que indica a presença de compostos com característica de eliciadores. A determinação da atividade biológica desses compostos, em relação à sua atividade eliciadora ou antimicrobiana, pode contribuir na aquisição de maiores conhecimentos para reforçar sua possível utilização como medida alternativa de controle para doenças de plantas.

Dentre as plantas medicinais, o guaco (Mikania glomerata Spreng.) se destaca entre as mais populares por suas propriedades medicinais como antiinflamatório (LORENZI; MATOS, 2002). Também é rico em cumarina, principal composto responsável por sua atividade medicinal (CELEGHINI; VILEGAS; LANÇAS, 2001). Porém, escassas são as informações do potencial dessa planta no controle de fitopatógenos, principalmente em sistema orgânico de produção de hortaliças.

Dentre as culturas produzidas organicamente destacam-se tomate, alface e couve-flor. Nesta cultura, apesar da disponibilidade de variedades/ híbridos com bons níveis de resistência às doenças, tem sido destacada a podridão negra causada pela bactéria Xanthomonas campestris pv. campestris, principal doença bacteriana das crucíferas (MARINGONI, 2005). 
Diante do exposto, o presente trabalho teve como objetivos avaliar o efeito da tintura vegetal da planta medicinal M. glomerata (guaco) na inibição do crescimento bacteriano de $X$. campestris pv. campestris; na indução de resistência local e/ou sistêmica e no acúmulo da enzima de defesa vegetal peroxidase em folhas de plantas de couve-flor tratadas.

\section{Material e Métodos}

\section{Dados do experimento}

Os estudos e avaliações foram realizados na Universidade Estadual do Oeste do Paraná Unioeste, campus de Marechal Cândido Rondon, no período de agosto a dezembro de 2002 e 2003.

\section{Obtenção e isolamento da bactéria}

$\mathrm{O}$ isolamento foi realizado a partir de folhas de couve-flor as quais apresentavam sintomas característicos provocados pela bactéria Xanthomonas campestris pv. campestris, provenientes de cultivos comerciais do município de Marechal Cândido Rondon/PR, de acordo com metodologia proposta por Mariano e Silveira (2000). Fragmentos das folhas, na área de transição tecido sadio e área lesionada, foram cortados, imergidos em álcool $50 \%$ por 30 seg e após em água +hipoclorito de sódio (3:1) por 1 min e, enxaguados em água destilada. Após a desinfestação superficial procedeuse a maceração em solução salina $(0,85 \%$ de $\mathrm{NaCl})$ esterilizada e, após, com alça de platina, transferiuse uma alíquota do macerado para placas de Petri contendo meio ágar-nutriente, distribuindo-se na forma de estrias compostas. Após, as placas foram etiquetadas, invertidas e incubadas a $25^{\circ} \mathrm{C}$.

\section{Obtenção da curva de crescimento bacteriano}

O crescimento bacteriano foi determinado pelo método de determinação da concentração do inóculo pela contagem em placas, descrito por Mariano e Assis (2000). Foram preparadas suspensões da bactéria teste a partir da cultura em placas e estas ajustadas em concentração bacteriana suficiente para obter leituras de 1,$2 ; 0,8 ; 0,4$ e 0,0 em absorbância a $580 \mathrm{~nm}$.

De cada uma das suspensões procedeu-se uma série de diluições, de modo a obter-se os valores indicados a seguir. Para a absorbância 1,2 foram feitas diluições até $10^{10}$ e, para as absorbâncias 0,8 e 0,4 diluições até $10^{9}$, sendo utilizadas as três últimas.

De cada uma das diluições pipetou-se $0,05 \mathrm{~mL}$ para cada placa de Petri com meio ágar-nutriente, sendo distribuídas uniformemente com auxílio de alça de vidro flambada e esfriada, com três repetições por diluição, as quais foram invertidas e incubadas a $25^{\circ} \mathrm{C}$ por $48 \mathrm{~h}$. Foram consideradas placas contáveis aquelas que apresentaram entre 30 e 300 colônias. Os dados de unidades formadoras de colônia (UFC) foram transformados para uma mesma base de $10^{10}$, para obtenção posterior de uma equação de regressão.

\section{Planta medicinal e obtenção da tintura etanólica}

Plantas de guaco, cultivadas na área experimental do campus da Unioeste em Marechal Cândido Rondon, foram colhidas em maio de 2002 para obtenção da tintura vegetal. Essa tintura (com 1/5 de seu peso em erva seca) foi obtida através de maceração das folhas $(100 \mathrm{~g})$ em álcool etílico $50^{\circ}$ G.L. (400 mL) por sete dias em geladeira. Após procedeu-se a filtragem da tintura etanólica em gaze e em papel filtro Whatman $n^{\circ} 01$. O álcool foi removido da tintura por roto-evaporação a $75^{\circ} \mathrm{C} \mathrm{sob}$ vácuo, obtendo-se uma pasta escura da qual foram preparadas diluições. Foram utilizadas concentrações de $100,250,500$ e $1000 \mathrm{mg} \mathrm{L}^{-1}$ da tintura.

\section{Atividade antimicrobiana in vitro da tintura}

Para este ensaio foi empregado o meio de cultura caldo nutriente (extrato de carne: $3 \mathrm{~g}$; peptona: $5 \mathrm{~g}$; glicose: $15 \mathrm{~g}$; água destilada: $1.000 \mathrm{~mL}$ ) (MARIANO; 
ASSIS, 2000) suplementado antes da autoclavagem com as concentrações indicadas diluídas em $50 \mathrm{~mL}$ de etanol $50^{\circ} \mathrm{GL}$. Apenas meio de cultura foi utilizado como controle. O meio com as diferentes concentrações da planta medicinal foi vertido em tubos de ensaio (10 mL/tubo) e à estes adicionou-se uma alíquota de $100 \mathrm{~mL}$ da suspensão de células bacterianas contendo $10^{10} \mathrm{UFC} \mathrm{mL}^{-1} \mathrm{e}$, na seqüência, procedeu-se a incubação a $25^{\circ} \mathrm{C}$ por $48 \mathrm{~h}$ em estufa incubadora sob agitação. $\mathrm{O}$ crescimento bacteriano foi determinado em espectrofotômetro, anotando-se a absorbância a $580 \mathrm{~nm}$ para cada amostra e calculando-se o valor de UFCs de acordo com a curva de crescimento bacteriano previamente elaborada. Como tratamentos controle foram empregados o meio de cultura ( $0 \mathrm{mg} \mathrm{L}^{-1}$ de tintura) e meio de cultura com álcool (500 mg L-1 de álcool $\left.50^{\circ} \mathrm{GL}\right)$.

Indução de resistência em couve-flor à X. campestris $p v$. campestris

Foram utilizadas plantas de couve-flor, variedade Teresópolis Gigante, semeadas em setembro de 2003, cultivadas em vasos plásticos contendo $0,5 \mathrm{~L}$ de uma mistura de solo e areia autoclavados e mantidas em casa de vegetação. Aos 25 dias de idade receberam, através de aspersão, os tratamentos com tintura de guaco na terceira folha. Os tratamentos controle foram água destilada (testemunha) e a calda bordaleza, representando o tratamento padrão utilizado pelos produtores em sistema orgânico de cultivo desta hortaliça. Concomitantemente e três dias após os tratamentos a terceira folha tratada e a quarta folha não tratada da mesma planta foram inoculadas por aspersão com $10^{10} \mathrm{UFC} \mathrm{mL}^{-1}$ de $X$. campestris pv. campestris. Após a inoculação, os vasos foram cobertos com saco plástico previamente umedecido, permanecendo em câmara úmida por $48 \mathrm{~h}$ e, na seqüência, mantidos em casa de vegetação até o surgimento dos sintomas (ROMEIRO, 2001). A severidade de doença foi estimada com o auxílio de escala diagramática previamente elaborada, cujos níveis de doença eram 3, 6, 10, 19, 36 e 69\% de área foliar lesionada. Os dados de severidade em plantas mantidas em casa de vegetação foram submetidos à análise de variância. O delineamento estatístico foi o inteiramente casualizado com quatro repetições.

Coleta de amostras para determinação da atividade de peroxidase

Foram retirados três discos/folha (com $2 \mathrm{~cm}$ de diâmetro) das plantas tratadas através de: a) aplicação de tintura e inoculação do patógeno concomitantemente e três dias após o tratamento; b) apenas aplicação de tintura; c) apenas inoculação do patógeno; d) sem aplicação de tintura e sem inoculação do patógeno. Os discos foram retirados das terceiras e quartas folhas nos tempos $0,24,48 \mathrm{e}$ $72 \mathrm{~h}$ após a aplicação da tintura (para o tratamento b) ou inoculação do patógeno (para os tratamentos a e c), colocados em tubos para microcentrífuga e armazenados a $-20{ }^{\circ} \mathrm{C}$ para posterior análise.

\section{Atividade de peroxidases}

Depois de coletadas, as amostras foram homogeneizadas em $4 \mathrm{~mL}$ de tampão fosfato de sódio 0,01 M (pH 6,0) (tampão de extração) em almofariz de porcelana. O sobrenadante obtido foi considerado como a fração contendo as peroxidases solúveis e armazenado a $4{ }^{\circ} \mathrm{C}$ para posterior determinação da atividade enzimática (STANGARLIN; PASCHOLATI; FRANZENER, 2005).

A atividade das peroxidases foi determinada à 30 ${ }^{\circ} \mathrm{C}$, através de método espectrofotométrico direto (HAMMERSCHMIDT; NUCLES; KUC, 1982). A mistura da reação constituiu de $2,5 \mathrm{~mL}$ de uma solução contendo $250 \mu \mathrm{L}$ de guaiacol e $306 \mu \mathrm{L}$ de peróxido de hidrogênio em $100 \mathrm{~mL}$ de tampão fosfato de sódio 0,01 M ( $\mathrm{pH} 6,0)$ e $0,5 \mathrm{~mL}$ de preparação enzimática. A cubeta de referência constituiu de 3,0 $\mathrm{mL}$ da solução anteriormente preparada. A reação foi seguida em espectrofotômetro a $470 \mathrm{~nm}$. Os resultados foram expressos em variação de unidades de absorbância/min/grama de peso fresco (STANGARLIN; PASCHOLATI; FRANZENER, 2005). 
Os dados foram submetidos a análise de variância segundo arranjo fatorial, num delineamento inteiramente ao acaso com dois fatores: tempo (quatro subníveis: 0, 24, 48 e $72 \mathrm{~h}$ após tratamento) e tratamentos (sete subníveis para terceira folha tratada: testemunha água, testemunha inoculada, 500 $\mathrm{mg} \mathrm{L}^{-1}$ três e 0 dias antes da inoculação, $100 \mathrm{mg} \mathrm{L}^{-1}$ três e 0 dias antes da inoculação e álcool $50^{\circ} \mathrm{GL} 500$ $\mathrm{mg} \mathrm{L}^{-1}$; seis subníveis para quarta folha não tratada: testemunha água, testemunha inoculada, $500 \mathrm{mg} \mathrm{L}^{-1}$ três e 0 dias antes da inoculação e $100 \mathrm{mg} \mathrm{L}^{-1}$ três e 0 dias antes da inoculação), com três repetições.

\section{Resultados e Discussão}

\section{Ação antibacteriana in vitro}

A reta dada pela equação de concentração bacteriana em função de valores de absorbância a $580 \mathrm{~nm}$ pode ser visualizada na Figura 1. O comportamento da concentração bacteriana em relação à absorbância foi linear, tendo como equação da reta $\mathrm{y}=411 \mathrm{x}-14,6$, com coeficiente de determinação $\left(R^{2}\right)$ igual a 0,9622 .

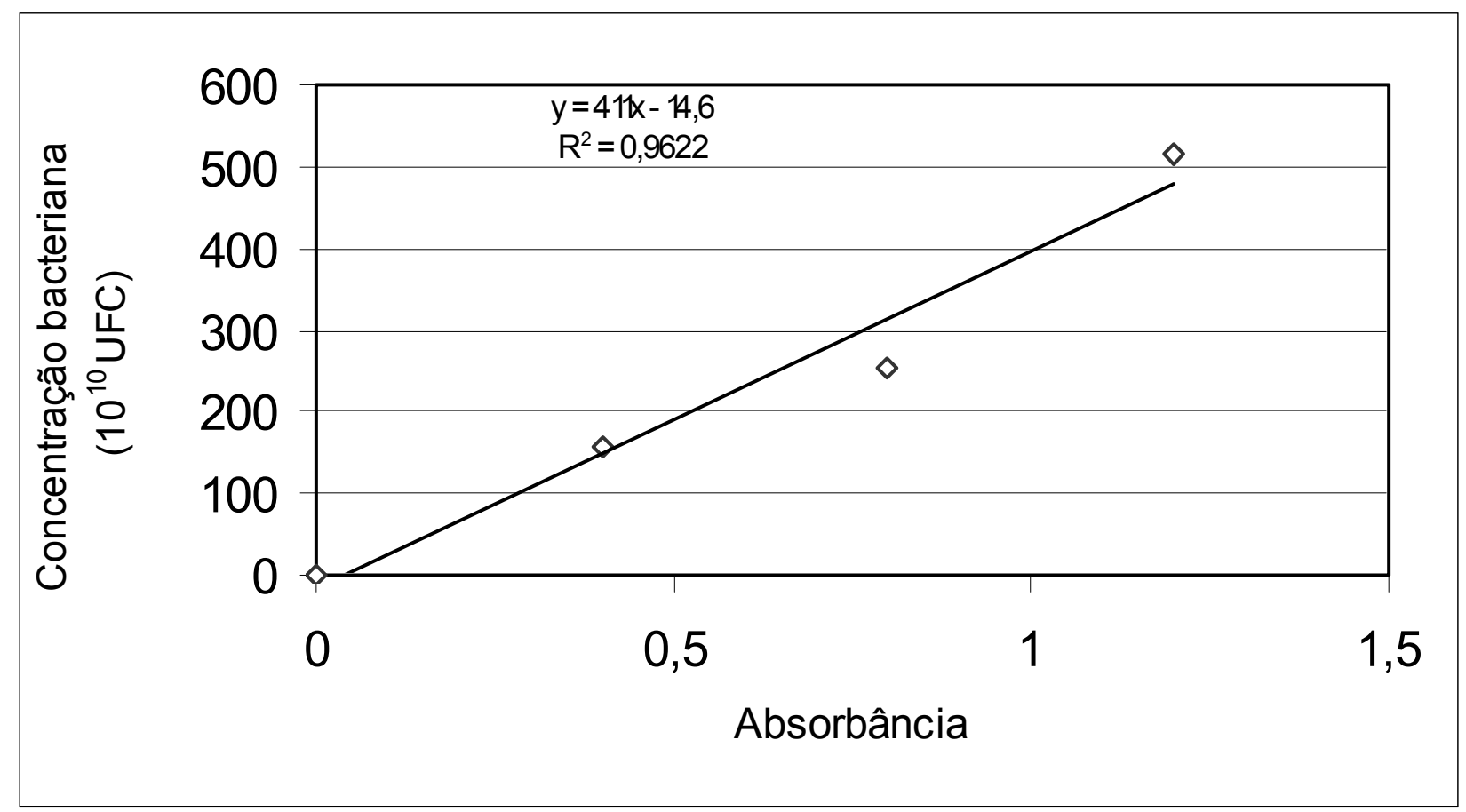

Figura 1. Ajuste da reta de concentração bacteriana (em unidades formadoras de colônias - UFC) em função da absorbância a $580 \mathrm{~nm}$.

O efeito das concentrações da tintura de guaco sobre $X$. campestris pv. campestris pode ser verificado na Figura 2. A tintura inibiu o crescimento bacteriano a partir da concentração de $250 \mathrm{mg} \mathrm{L}^{-1}$, pois até este ponto não diferiram das testemunhas 0 mg L ${ }^{-1}$ de tintura e álcool $50{ }^{\circ} \mathrm{GL}$ a $500 \mathrm{mg} \mathrm{L}^{-1}$. A concentração de tintura $500 \mathrm{mg} \mathrm{L}^{-1}$ inibiu em $24 \%$ o crescimento em relação a testemunha. 


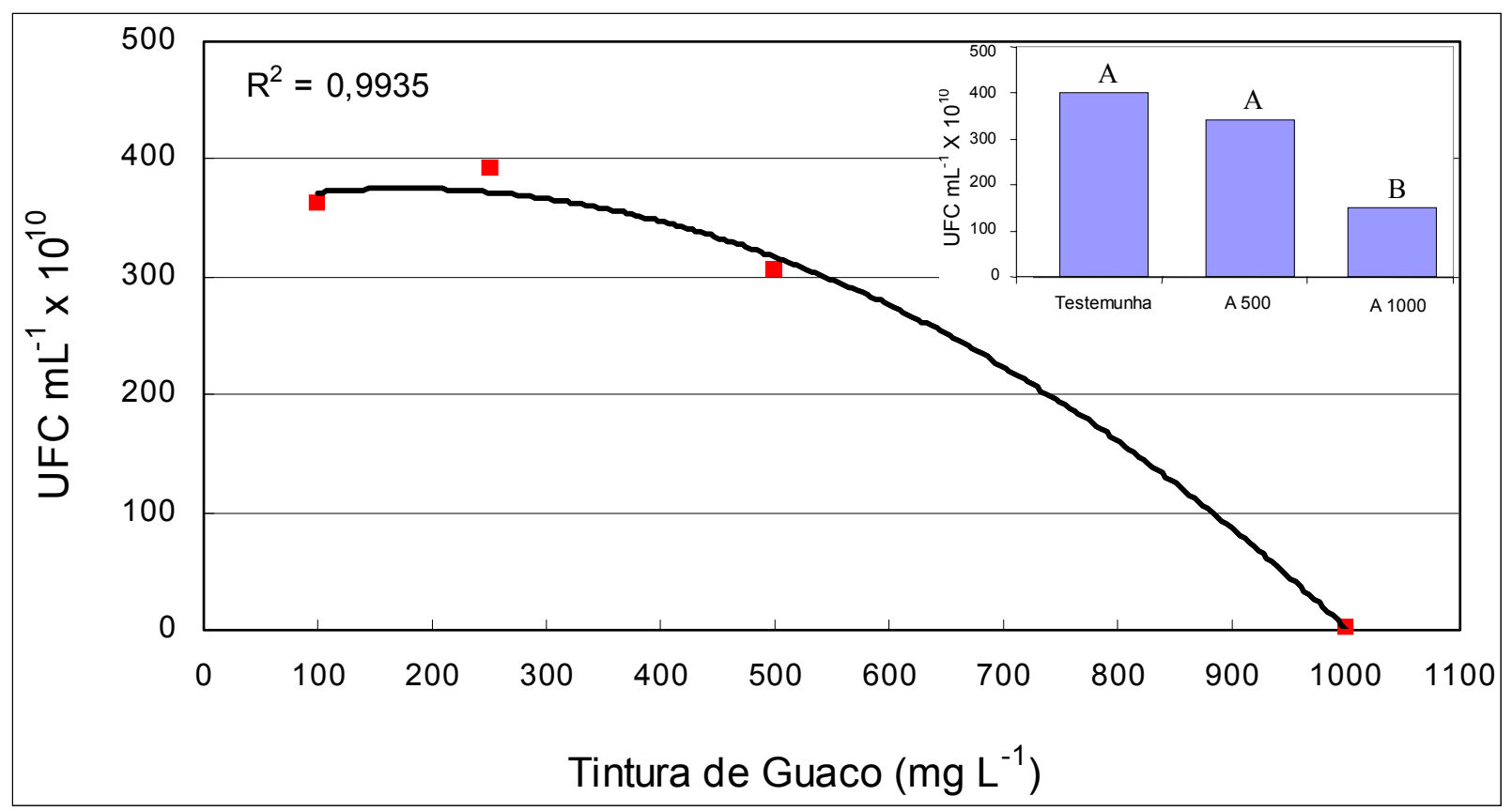

Figura 2. Efeito da tintura etanólica de M. glomerata (guaco) sobre o crescimento in vitro de $X$. campestris pv. campestris (expresso em unidades formadoras de colônia - UFC). Para o quadro inserido: testemunha = apenas meio de cultura; A 500 e A $1000=$ meio de cultura contendo 500 e $1000 \mathrm{mg} \mathrm{L}^{-1}$ de etanol $50^{\circ} \mathrm{GL}$, respectivamente. Letras maiúsculas distintas sobre as barras indicam diferença pelo teste de Tukey $5 \%$.

Para a tintura a $1000 \mathrm{mg} \mathrm{L}^{-1}$, o crescimento bacteriano in vitro foi reduzido em aproximadamente $98 \%$, embora cerca de $60 \%$ desta redução tenha sido ocasionada pelo etanol $50^{\circ} \mathrm{GL}$ usado no preparo da tintura (valor obtido descontando-se o crescimento bacteriano no tratamento que continha apenas etanol). Os restantes $38 \%$ de inibição podem ser atribuídos a compostos antibacterianos presentes na tintura de guaco. Este efeito pode estar relacionado a atividade antiinflamatória de extratos hidroalcoólicos de $M$. glomerata, relatada por Celeghini, Vilegas e Lanças (2001).

Trabalhos realizados utilizando-se plantas medicinais no controle de bacterioses têm demonstrado alguns resultados satisfatórios. Becker (2003), em trabalhos realizados em pepino contra mancha angular causada por Pseudomonas syringae pv. lachrymans observou total inibição do crescimento bacteriano com aplicação do extrato bruto aquoso de capim-limão e carqueja, respectivamente, nas concentrações de 20 e $25 \%$. O mesmo observaram Kuhn et al. (2006) com extrato aquoso de cúrcuma, para controle de Xanthomonas axonopodis pv. manihotis em mandioca, com inibição total do crescimento bacteriano já na concentração de $10 \%$ do extrato.

Atividade da peroxidase em folhas de couve-flor

Os resultados da atividade de peroxidase em folhas de couve-flor tratadas com a tintura de guaco estão apresentados na Tabela 1. A atividade foi superior nas plantas que receberam apenas a inoculação da bactéria, quando comparada aos demais tratamentos, embora sem diferença estatística pelo teste de Tukey 5\%, exceção ao tratamento etanol 50 ${ }^{\circ} \mathrm{GL} 500 \mathrm{mg} \mathrm{L}^{-1}$. Com base nesses resultados concluise que a indução de peroxidases ocorreu devido ao processo infeccioso, sem ocorrer a indução dessa enzima nos tratamentos com tintura etanólica de guaco. O fato de não terem sido observadas diferenças significativas entre os tratamentos e a testemunha água, reforça mais uma vez a idéia de que a tintura de $M$. glomerata não é eficaz na indução de peroxidases em couve-flor. 
Tabela 1. Atividade de peroxidase na terceira e quarta folhas de couve-flor tratadas com diferentes concentrações de Mikania glomerata (guaco) antes e concomitantemente a inoculação com Xanthomonas campestris pv. campestris.

\begin{tabular}{|c|c|c|}
\hline Tratamentos & $3^{\text {a }}$ folha & $4^{\mathrm{a}}$ folha \\
\hline Água & $0,0154^{1} \mathrm{AB}^{2}$ & $0,0192 \mathrm{~A}$ \\
\hline Apenas inoculação c/ patógeno & $0,0351 \mathrm{~A}$ & $0,0252 \mathrm{~A}$ \\
\hline Tintura $500 \mathrm{mg} \mathrm{L}^{-1}(-3 \text { dias })^{3}$ & $0,0242 \mathrm{AB}$ & $0,0361 \mathrm{~A}$ \\
\hline Tintura $500 \mathrm{mg} \mathrm{L}^{-1}(0 \mathrm{dia})^{4}$ & $0,0150 \quad \mathrm{AB}$ & $0,0164 \mathrm{~A}$ \\
\hline Tintura $100 \mathrm{mg} \mathrm{L}^{-1}(-3 \text { dias })^{3}$ & $0,0130 \quad \mathrm{AB}$ & $0,0150 \mathrm{~A}$ \\
\hline Tintura $100 \mathrm{mg} \mathrm{L}^{-1}(0 \mathrm{dia})^{4}$ & $0,0212 \mathrm{AB}$ & $0,0211 \mathrm{~A}$ \\
\hline Etanol $50^{\circ} \mathrm{GL} 500 \mathrm{mg} \mathrm{L}^{-1}$ & $0,0063 \mathrm{~B}$ & $0,0114 \mathrm{~A}$ \\
\hline
\end{tabular}

${ }^{1}$ Valores de atividade enzimática expressos em D U.A./min/grama de peso fresco, onde D U.A. é a variação nas unidades de absorbância a $470 \mathrm{~nm}$.

${ }^{2}$ Médias seguidas de mesma letra, na coluna, não diferem entre si pelo teste de Tukey $5 \%$.

${ }^{3} \mathrm{e}^{4}$ Tratamentos realizados três dias antes ou concomitantemente, respectivamente, à inoculação com o patógeno. Os tratamentos foram realizados apenas na $3^{\mathrm{a}}$ folha, enquanto que a inoculação ocorreu nas $3^{\mathrm{a}} \mathrm{e} 4^{\mathrm{a}}$ folhas.

Georgieva et al. (2002), na avaliação de peroxidase e â-glicosidase em frutos de tomate infectados por vírus, bactéria e fungo, verificaram aumento da peroxidase pelo simples processo infeccioso e avanço da colonização pelos patógenos. Também Kagade et al. (2004), quantificando a atividade de peroxidase em folhas de arroz tratadas com extrato de Datura metel, observaram que os maiores valores foram em plantas que além do extrato, foram inoculadas com a bactéria Xanthomonas oryzae pv. oryzae. Gay e Tuzun (2000), ao avaliarem a atividade de peroxidase em hidatódios de plantas de variedades de repolho suscetíveis e resistentes, inoculadas com $X$. campestris pv. campestris, verificaram maior atividade da enzima nas resistentes quando comparadas às suscetíveis, mostrando o importante papel dessa enzima na resposta de defesa da planta ao patógeno.
Severidade da podridão negra em couve-flor causada pela bactéria $X$. campestris pv. campestris

Para os tratamentos 500 e $100 \mathrm{mg} \mathrm{L}^{-1}$ de tintura aplicados concomitantemente com a bactéria, foi observada redução na severidade da doença na terceira folha das plantas de couve-flor inoculadas (Tabela 2). O resultado foi idêntico ao da calda bordaleza (tratamento controle), um produto protetor a base de cobre, o que confere à tintura de guaco, um aspecto de controle por atividade antimicrobiana direta. Para os tratamentos 500 e $100 \mathrm{mg} \mathrm{L}^{-1} \mathrm{de}$ tintura, aplicados três dias antes da inoculação, não foi observada diferença estatística quando comparada à testemunha, embora a média de severidade tenha sido $40 \%$ menor, o que indica a existência de efeito residual da tintura relacionado com a sua atividade antimicrobiana ou mesmo, indução local de resistência. 
Tabela 2. Controle de Xanthomonas campestris pv. campestris em plantas de couve-flor tratadas com tintura de Mikania glomerata ou calda bordaleza.

\begin{tabular}{|c|c|c|}
\hline \multirow{2}{*}{ Tratamentos $^{1}$} & \multicolumn{2}{|c|}{ Severidade $(\%)^{2}$} \\
\hline & $3^{\text {a }}$ folha & 4⿳亠口冋丁 folha \\
\hline Testemunha & $50 \mathrm{~A}^{3}$ & $31 \mathrm{~A}$ \\
\hline Tintura $500 \mathrm{mg} \mathrm{L}^{-1}(-3 \text { dias })^{4}$ & $39 \mathrm{~A}$ & $33 \mathrm{~A}$ \\
\hline Tintura $100 \mathrm{mg} \mathrm{L}^{-1}(-3 \text { dias })^{4}$ & $18 \mathrm{AB}$ & $27 \mathrm{~A}$ \\
\hline Tintura $500 \mathrm{mg} \mathrm{L}^{-1}(0 \text { dia })^{5}$ & $6 \mathrm{~B}$ & $5 \mathrm{~A}$ \\
\hline Tintura $100 \mathrm{mg} \mathrm{L}^{-1}(0 \mathrm{dia})^{5}$ & $9 \mathrm{~B}$ & $9 \mathrm{~A}$ \\
\hline Calda bordaleza ${ }^{6}$ & $6 \mathrm{~B}$ & $33 \mathrm{~A}$ \\
\hline
\end{tabular}

${ }^{1}$ Tratamentos realizados na terceira folha;

${ }^{2}$ Severidade avaliada 20 dias após a inoculação da bactéria que ocorreu na terceira e quarta folhas;

${ }^{3}$ Médias seguidas de mesma letra, na coluna, não diferem entre si pelo teste de Tukey $1 \%$;

${ }^{4} \mathrm{e}^{5}$ Tratamentos realizados três dias antes ou concomitantemente, respectivamente, à inoculação com o patógeno;

${ }^{6}$ Tratamento padrão utilizado pelos produtores orgânicos de Marechal Cândido Rondon.

Para a quarta folha não tratada e inoculada, não foram observadas diferenças estatísticas na severidade entre os tratamentos na comparação com a testemunha, indicando haver somente atividade localizada da tintura na planta, e o tratamento controle com calda bordaleza comportou-se dessa mesma forma.

Considerando a importância da peroxidase no mecanismo de defesa de crucíferas a $X$. campestris pv. campestris (GAY; TUZUN, 2000) e a ausência de ativação desta enzima pela tintura de guaco, podese concluir que a redução da severidade da doença no presente estudo ocorreu pela atividade antimicrobiana conferida pela tintura de guaco. Portanto, a tintura de guaco pode representar uma alternativa no manejo para o controle da podridão negra em couve-flor. Novos estudos buscando potencializar o emprego desta planta bem como elucidar os mecanismos envolvidos, se fazem necessários. No entanto, outros mecanismos podem estar envolvidos e outros solventes para obtenção do extrato podem ser estudados.

\section{Referências}

BECKER, A. Universidade Estadual do Oeste do Paraná produzido em cultivo orgânico e protegido. 2003. Trabalho de Conclusão de Curso (Graduação em Agronômia) - Universidade Estadual do Oeste do Paraná, Marechal Cândido Rondon.

BONALDO, S. M.; SCHWAN-ESTRADA, K. R .F.; STANGARLIN, J. R.; TESSMANN, D. J.; SCAPIM, C. A. Fungitoxidade, atividade elicitora de fitoalexinas e proteção de pepino contra Colletotrichum lagenarium, pelo extrato aquoso de Eucalyptus citriodora. Fitopatologia Brasileira, Brasília, v.29, n.2, p.128-134, 2004.

CELEGHINI, R. M. S.; VILEGAS, J. H. Y.; LANÇAS, F. M. Extraction and quantitative HPLC analysis of coumarin in hydroalcoholic extracts of Mikania glomerata Spreng. ("guaco") leaves. Journal Brazilian Chemical Society, São Paulo, v.12, n.6, p.706-709, 2001.

FIORI, A. C. G.; SCHWAN-ESTRADA, K. R. F.; STANGARLIN, J. R.; VIDA, J. B.; SCAPIM, C. A; CRUZ, M. E. S.; PASCHOLATI, S. F. Antifungal activity of leaf extracts and essential oils of some medicinal plants against Didymella bryoniae. Journal of Phytopathology, Berlin, v.148, p.483-487, 2000.

GAY, P. A.; TUZUN, S. Involvement of a novel peroxidase isozyme and lignification in hydathodes in resistance to black rot disease in cabbage. Canadian Journal of Botany, Ottawa, v.78, n.9, p.1144-1149, 2000. 
GEORGIEVA, I.D.; EDREVA, A.; RODEVA, R.; SOTIROVA, V.; STOIMENOVA, E. Peroxidase and b-glucosidase responses of tomato fruits to viral, bacterial and fungal infections. Disponível em: <http://www.unige.ch/LABPV/ perox.html>. Acesso em: 22 jan. 2002.

GHINI, R.; KIMATI, H. Resistência de fungos a fungicidas. Jaguariúna: Embrapa - Meio Ambiente, 2000.

HAMMERSCHMIDT, R.; NUCLES, E. M.; KUC, J. Association of enhanced peroxidase activity with induced systemic resistance of cucumber to Colletotrichum lagenarium. Physiological Plant Pathology, London, v.20, n.1, p.73-82, 1982.

KAGADE, S.; MARIMUTHU, T.; THAYUMANAVAN, B.; NANDAKUMAR, R.; SAMIYAPPAN, R. Antimicrobial activity and induction of resistance in rice by leaf extract of Datura metel against Rhizoctonia solani and Xanthomonas oryzae pv. oryzae. Physiological and Molecular Plant Pathology, London, v.65, p.91-100, 2004.

KARAMAN, Í.; SAHIN, F.; GÜLLÜCE, M.; ÖGÜTÇÜ, H.; SENGÜL, M.; ADIGÜZEL, A.. Antimicrobial activity of aqueous and methanol extracts of Juniperus oxycedrus L. Journal of Ethnopharmacology, Lausanne, v.85, n.2/3, p.231-235, 2003.

KUHN, O. J.; PORTZ, R. L.; STANGARLIN, J. R.; DEL ÁGUILA, R. M.; SCHWAN-ESTRADA, K. R. F.; FRANZENER, G. Efeito do extrato aquoso de cúrcuma (Curcuma longa) em Xanthomonas axonopodis pv. manihotis. Semina-Ciências Agrárias, Londrina, v.27, n.1, p.13-20, 2006.

LORENZI, H.; MATOS, F. J. A. Plantas medicinais no Brasil: nativas e exóticas. Nova Odessa: Instituto Plantarum, 2002.
MARIANO, R. L. R.; SILVEIRA, E. B. Isolamento de bactérias fitopatogênicas. In: MARIANO, R. L. R. Manual de Práticas em Fitobacteriologia. Recife: Editora da Universidade Federal Rural de Pernambuco, 2000. p.27-35.

MARIANO, R. L. R.; ASSIS, S. M. P. Quantificação de inóculo de bactérias fitopatogênicas. In: MARIANO, R. L. R. Manual de Práticas em Fitobacteriologia. Recife: Editora da Universidade Federal Rural de Pernambuco, 2000.p.49-52.

MARINGONI, A. C. Doenças das crucíferas. In: KIMATI, H.; AMORIM, L.; REZENDE, J. A M.; BERGAMIN FILHO, A; CAMARGO, L. E. A. Manual de Fitopatologia: doenças da plantas cultivadas. 4.ed. São Paulo: Agronômica Ceres, 2005. v.2, cap.31, p.385-391.

ROMEIRO, R. S. Métodos em bacteriologia de plantas. Viçosa: Editora da UFV, 2001.

SCHWAN-ESTRADA, K. R.F. Potencial de extrato e óleos essenciais de vegetais como indutores de resistência plantas medicinais. In: REUNIÃO BRASILEIRA SOBRE INDUÇÃO DE RESISTÊNCIA EM PLANTAS CONTRA FITOPATÓGENOS, 1., 2003, São Pedro. Anais... São Pedro: [s.n.], 2003

STANGARLIN, J. R.; PASCHOLATI, S. F.; FRANZENER, G. Phenols, â-1,3 glucanase, chitinase and phenylalanine ammonia-lyase activities in infection sites of Exserohilum turcicum in maize genotypes. Summa Phytopathologica, Jaguariuna, v.31, n.3, p.261-267, 2005.

STANGARLIN, J. R.; SCHWAN-ESTRADA, K. R. F.; CRUZ, M. E. S.; NOZAKI, M. H. Plantas medicinais e controle alternativo de fitopatógenos. Biotecnologia Ciência \& Desenvolvimento, Brasília, v.6, n.11, p.16-21, nov./dez. 1999. 